\title{
ASPECTOS HISTÓRICOS DOS SISTEMAS DE NUMERAÇÃO EM UM LIVRO DE ARITMÉTICA PUBLICADO NO CEARÁ EM 1904
}

\section{HISTORICAL ASPECTS OF NUMERAL SYSTEMS IN AN ARITHMETIC TEXTBOOK PUBLISHED IN CEARÁ IN 1904}

\author{
Elenice de Souza Lodron Zuin ${ }^{1}$ \\ Pontifícia Universidade Católica de Minas Gerais
}

\begin{abstract}
Resumo
Neste artigo, trazemos um recorte de um estudo sobre a obra Lições de Arithmetica, de Odorico Castello Branco, publicada, em 1904, em Fortaleza, Ceará. Fazemos uma descrição e análise dos aspectos históricos referentes aos sistemas de numeração incluídos no referido livro. Nossa pesquisa envereda-se pela História das Disciplinas Escolares, vinculada à História da Educação Matemática, ao apontar um autor que traz uma metodologia distinta para o tratamento dos sistemas de numeração. Ao mesmo tempo, discutimos as informações históricas presentes no livro. Esse viés histórico, em geral, não era encontrado em outros livros da Aritmética escolar publicados em fins do século XIX e início do século XX no Brasil. Ficaria demarcada a concepção de Castello Branco trazendo uma abordagem distinta, provavelmente, imbuído da intenção de romper com o caráter formal do ensino da Aritmética naquela época? Como fundador e diretor do Instituto Miguel Borges, em Fortaleza, no ano de 1900, ele adotou suas obras na instituição, o que leva a crer que, na sua escola, o ensino de Aritmética seguia o seu texto. As evidências apontam que o autor parecia buscar inculcar novos saberes e outra maneira de transmissão de um conteúdo. Algumas hipóteses, para que Castello Branco agregasse componentes históricos ao seu livro, emergem, sem, contudo, alcançarem um patamar conclusivo. Ainda que este autor pudesse ter outras influências, nossos estudos nos levam a inferir que suas principais fundamentações se ancoram em Histoire des Mathématiques, de Ferdinand Hoefer, e na Arithmetica dos irmãos Aarão e Lucano Reis.
\end{abstract}

Palavras-chave: História da Matemática; Sistema de Numeração; Aritmética escolar.

\begin{abstract}
In this paper, we present considerations regarding our research about the textbook Lições de Arithmetica, by Odorico Castello Branco, published in 1904, in Fortaleza, Ceará. We describe and analyze the historical aspects of the numeral systems included in this book. Our research encompasses the History of School Disciplines and intends to contribute to the History of Mathematics Education in Brazil, highlighting an author who has a different methodology for numeral systems. Historical information on this topic, in general, was not found in other arithmetical textbooks published in the late $19^{\text {th }}$ and early $20^{\text {th }}$ centuries in Brazil. Could it be that with this different approach, Castelo Branco intended to break with the formal character of Arithmetic teaching at that time? As founder and director of Instituto Miguel Borges, in the year 1900 in Fortaleza, he
\end{abstract}

\footnotetext{
1 elenicezuin@gmail.com
} 
Elenice de Souza Lodron Zuin

Aspectos históricos dos sistemas de numeração em um livro de aritmética publicado no Ceará em 1904 adopted not only his old textbooks in his school but also, most likely, Lições de Arithmetica. The evidences found indicate that the author proposed a new approach to the teaching of numeral systems, and included this new knowledge in his textbooks. Although Castello Branco could have other influences, our studies lead us to believe that his main foundations are based on the books Histoire des Mathématiques, by Ferdinand Hoefer, and Arithmetica by the brothers Aarão and Lucano Reis.

Keywords: History or Mathematics; Numeral Systems; Elementary Arithmetic.

\section{Introdução}

No Brasil, vem crescendo as pesquisas sobre a História das Disciplinas Escolares nas últimas décadas. Algumas das investigações focam determinados conteúdos escolares e/ou aspectos metodológicos ligados a correntes pedagógicas e/ou à legislação. Para proceder a estes estudos, uma das fontes primárias mais utilizadas têm sido os impressos com destinação pedagógica. "A análise dos livros escolares permite inferências quanto aos objetivos e metodologia, subjacentes ou explícitos, que o autor transmite para o seu leitor." (ZUIN, 2007, p. 16). As concepções do autor das obras também se inscrevem, de forma direta ou sutil, nas entrelinhas do texto, permitindo inferências.

Embora existam diversas pesquisas relativas à História da Educação Matemática no Brasil, muitas lacunas ainda se fazem sentir. Investigações que tenham como foco a presença da História da Matemática em livros didáticos no século XIX e primeiras décadas do século XX ainda são incipientes. Podemos citar dois trabalhos que caminham por este viés: História da Matemática e positivismo nos livros didáticos de Aarão Reis (GOMES, 2008) e Abordagens históricas da matemática em "Lições de Álgebra Elementar” de Joaquim Ignácio de Almeida Lisboa (ZUIN; SANTOS, 2017).

No início do século XX, vamos encontrar o professor Odorico Castello Branco, que publicou, em 1904, suas Lições de Arithmetica, incluindo algumas abordagens históricas, quando era pouco comum que os autores dos textos da Aritmética escolar estivessem empenhados em ressaltar aspectos da História da Matemática. As minhas pesquisas em livros de Aritmética publicados no século XIX e início do século XX, há vários anos, indicam um maior número de autores que não seguem essa linha.

Chervel (1990) defende que os conteúdos passam por transformações e a função das disciplinas escolares "consiste em cada caso em colocar um conteúdo de instrução a serviço de uma finalidade educativa." (p. 188). Dentro deste contexto, a abordagem 
Elenice de Souza Lodron Zuin

Aspectos históricos dos sistemas de numeração em um livro de aritmética publicado no Ceará em 1904

histórica, encontrada no livro de Castello Branco, teria uma finalidade educativa, que o autor desejaria imprimir em seu texto.

Neste artigo, apresento uma descrição e análise do livro de Castello Branco, destacando os aspectos históricos, presentes na sua obra, relativamente aos sistemas de numeração.

\section{O autor e suas Lições de Arithmetica}

Odorico de Carvalho Castello Branco (1876-1921) nasceu na fazenda Desígnio, município de União, no Piauí. Ficou órfão na infância e foi criado por sua tia Candida Rosa Leal Castello Branco, na cidade de Teresina. Cursou o secundário no Colégio Nossa Senhora das Dores, dirigido por seu tio Miguel de Souza Borges Leal Castello Branco. Mais tarde, transferiu-se para o Ceará e matriculou-se na Escola Militar, trancando a matrícula posteriormente, se dedicando ao magistério (MENEZES, 1989).

Castello Branco relata, na conclusão do primeiro volume do seu livro, que iniciou a escrita do mesmo em 1897, quando ainda era soldado do $2^{\circ}$ Batalhão de Infantaria do Exército, aproveitava as horas vagas também para “dar lições” que aumentavam o seu pequeno soldo. Tornou-se professor e, no ano de 1900, fundou o Instituto Miguel Borges ${ }^{2}$, em Fortaleza, prosseguindo como diretor da escola durante a sua vida. Depois do seu falecimento, a instituição recebeu o seu nome. Castello Branco escreveu diversos compêndios, os quais eram adotados no Instituto (MENEZES, 1989).

Após iniciar a sua carreira como mestre-escola, Castello Branco dedicou-se mais ao seu livro de Aritmética, concluindo-o, ao que parece, em 1903, em meio aos afazeres de docente e, como ele mesmo relata, "fez um esforço enorme" dedicando "o melhor dos poucos momentos de repouso" que lhe deixava "uma centena de creanças"; acrescentando, "trabalharei ainda e cada vez mais, procurando não só adquirir conhecimentos novos, que tudo é novo para mim, como aperfeiçoar o quase nada de que disponho.” (CASTELLO BRANCO, 1904, p. 411).

O livro, Lições de Arithmetica, impresso em Fortaleza, na Tipografia Minerva, está dividido em duas partes, denominadas volumes. A primeira, intitulada Arithmetica

\footnotetext{
${ }^{2}$ O Instituto Miguel Borges, inicialmente, ocupou o casarão da Rua Major Facundo, 156-B, em Fortaleza. No ano de 1910, transferiu-se para a Rua Senador Pompeu, 24, em seguida, para a Praça Senados José Júlio (Praça Coração de Jesus) - permanecendo neste local até 1921. Depois do falecimento de Castello Branco, para homenageá-lo, a instituição ganhou o seu nome, "teve seu patrimônio alienado pela Arquidiocese de Fortaleza e mudou-se para a Avenida Dom Manuel no final da década de 1930". (Informações obtidas no site: http://www.fortalezaemfotos.com.br/2012/02/colegio-castelo-branco.html).
} 
Elenice de Souza Lodron Zuin

Aspectos históricos dos sistemas de numeração em um livro de aritmética publicado no Ceará em 1904

pura, editada em 1904, contendo 412 páginas e, a segunda, Applicações, com 55

páginas, lançada em 1905. Os conteúdos do livro apresentam a seguinte sequência:

Arithmetica pura: Numeração, Numeração Falada, Systema Decimal, Numeração Escrita, Sistema Grego e Romano, Sistema Atual, Sistemas

Diferentes do Decimal, Representações e Leitura de Frações, Operações Addição, Subtração, Multiplicação, Divisão, Potenciação, Radiciação, Divisibilidade, Razões e Proporções, Progressões, Logaritmos.

Applicações: Metrologia, Sistema Métrico Decimal, Regra de Três, Regra de Sociedade, Descontos, Cambio, Anuidades.

No prefácio do primeiro volume, o autor apresenta o seu livro:

Se aquillo que muito nos custa, de quanto nos custa, augmenta em valor, certo este livrinho vale alguma cousa; que em tanto avalio o que elle a mim me tem custado em noites perdidas, dissabores e decepções.

Agora, leitor, se a obra não te agrada, queima-a; mas por Deus, perdoa ao pobre autor o crime de seu amor pelo trabalho.

Releva, entretanto, uma observação; não quero, ao de ignorante, juntar o diploma de presumindo: - tudo o que ahi se encontra, salvo os disparates, existe mais ou menos em todos os compêndios; e alguma cousa tenha quase que transcripto.

As iniciaes seguintes, escriptas após uma proposição, demonstração, etc, indicam os autores a quem recorri.

M. Dr. F. Marcondes - Apontamentos de Arithmetica - Ceará -1901.

V. Dr. João José Luis Vianna - Elementos de Arithmetica - $6^{\mathrm{a}}$ ed. - Rio 1897.

S. Drs. Samuel de Oliveira e Liberato Bittencourt - Arithmetica - $1^{\text {a }}$ edição Capital Federal - 1897.

C. Coronel Luis Celestino de Castro - Arithmetica - $2^{\mathrm{a}}$ edição - Porto Alegre 1894.

C. C. Charles de Comberousse - Arithmétique - $3^{\text {iemm }}$ ed. - Paris - 1884.

B. Bourdon - Arithmétique - $3^{\text {ieme }}$ ed. v Paris 1878.

Ser. Serrasqueiro - Arithmetica - 13 ${ }^{\mathrm{a}}$ edição - Coimbra 1895.

São estes os mestres a quem mais luzes pedi; o que, de modo algum, me desliga de minha obrigação para com outros.

Que o crítico sincero me advirá de meus erros, em proveito meu e daquelles que minha ignorância poderia prejudicar; quanto porem aos critiqueiros de rodas de cafés, incapazes de qualquer esforço em beneficio seu ou de alguém, e, por isso, mesmo, sempre armados contra aquelles que trabalham, a elles o meu desprezo. Ceará - Abril - 1903. (CASTELLO BRANCO, 1904, p. IIIIV).

Observa-se que, Castello Branco teve como referência livros de autores consagrados naquela época, como era o caso dos franceses Charles de Comberouse e 
Elenice de Souza Lodron Zuin

Aspectos históricos dos sistemas de numeração em um livro de aritmética publicado no Ceará em 1904

Louis-Pierre-Marie Bourdon, do português José Adelino Serrasqueiro, porém, não deixa de lado autores brasileiros.

No início do segundo volume, o autor faz uma advertência ao leitor: "Mais ainda, se é possível, do que em redução ao primeiro volume, errará quem procurar neste QUALQUER COUSA devida exclusivamente a mim". Contudo, esse distanciamento do autor da sua obra - o que é compilação/tradução e o que não é - não fica bem definido.

Em alguns momentos, Castello Branco faz referência ao autor consultado, com citações em nota de rodapé. Entretanto, em uma delas justifica que teve acesso à obra Apontamentos de Arithmetica do Dr. Marcondes ${ }^{3}$ depois de ter escrito uma parte do livro e que verificou semelhanças.

Apesar de o livro de Marcondes ter sido publicado pela primeira vem em 1897, Castello Branco garante que não o conhecia e acrescenta: "Ahi fica a explicação. Quem quer que se dê ao trabalho de ler este livro comprehenderá facilmente que eu não me dou bem no papel de copista.” (1904, p. 47). A partir dessa informação, é possível acreditar que há trechos originais nas Lições de Arithmetica.

\section{Aspectos históricos dos sistemas de numeração no livro}

Um diferencial na obra refere-se à presença de aspectos históricos, pontuados ao longo de quinze páginas, quando o autor aborda os sistemas de numeração, algo pouco comum em outros livros de Aritmética da época:

Para a representação dos números os gregos juntaram ás vinte e quatro letras de seu alphabeto três outros caracteres e com estes vinte e sete symbolos representavam as três ordens da primeira classe, servindo nove symbolos para cada ordem segundo o numero de unidades nella existentes.

Os symbolos empregados para representação das unidades e dezenas simples serviam para exprimir as unidade e dezenas de milhares - myriades - e um numero qualquer de myriades se exprimia por meio dos mesmos caracteres seguidos da inicial Mu.

Dispunham portanto os gregos de elementos para a representação dos números até nove mil novecentos e noventa e nove unidades; ou noventa e nove milhões, novecentas noventa e nove unidades; ou noventa e nove milhões, novecentas noventa e nove mil, novecentas noventa e nove unidades.

A isto se limitava seu systema de numeração escripta; e era quanto bastava ás suas necessidades ordinárias. Entretanto foi proposto por Archimedes, como problema, representar um numero qualquer, por maior que fosse; mas os meios por elle empregados na solução da questão não podem ser expostos aqui. (CASTELLO BRANCO, 1904, p. 16).

\footnotetext{
3 Ao que tudo indica, trata-se de Francisco Marcondes Pereira, nascido em Fortaleza em 7/10/1866, formado em Engenharia, autor de vários livros e professor do Liceu do Ceará.
} 
Elenice de Souza Lodron Zuin

Aspectos históricos dos sistemas de numeração em um livro de aritmética publicado no Ceará em 1904

Neste ponto, o autor traz uma nota de rodapé, sugerindo o livro Histoire des mathématiques de V. Hoeffer (sic).

Continuando com a parte histórica, Castello Branco trata dos algarismos romanos, dedicando-lhes três páginas, das quais transcrevemos um trecho:

\begin{abstract}
Os romanos não empregavam, como os grego, todas as letras do alphabeto na representação dos números; tambem muito differentes das dos gregos as convenções entre elles estabelecidas para esse fim.

A letra I representava a unidade; e repetida II, III, os números dois e tres.

$\mathrm{V}$ representava cinco; e para, exprimir o numero quatro, faziam preceder a esta letra de I, ficando assim o valor della diminuído do desta; e escrevendo I, II, III, á direita de V, era este valor augmentado daquelles, ficando assim representados os números seis, sete e oito.

Para o valor dez era empregada a letra X a qual, precedida de I, seu valor ficava diminuído de uma unidade e portanto IX representava nove. (CASTELLO BRANCO, 1904, p. 16-17).
\end{abstract}

Desse modo, prossegue, explicando a forma de representação dos algarismos romanos e incluindo, um quadro sintético (figura 1), indicando o grande alcance da representação com os algarismos romanos a partir de poucos símbolos.

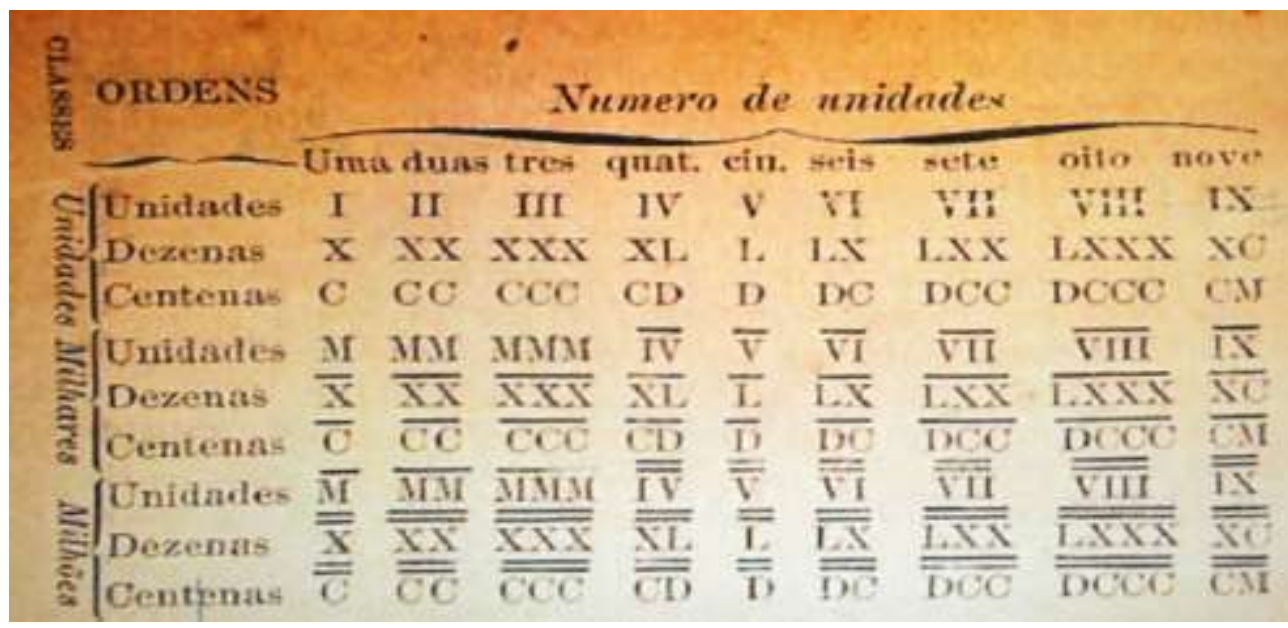

Figura 1 - Quadro síntese das representações com algarismos romanos

Fonte: Castello Branco (1904, p. 18)

Castello Branco justifica a importância dos algarismos romanos dizendo que "ainda entre nós este systema de numeração tem differentes empregos, como na numeração de capitulos de obras, nas indicações dos mostradores de relogios, nas datas dos monumentos, etc; razão por que temos procurado estudá-lo com algum desenvolvimento.” (CASTELLO BRANCO, 1904, p. 16). 
Elenice de Souza Lodron Zuin

Aspectos históricos dos sistemas de numeração em um livro de aritmética publicado no Ceará em 1904

$\mathrm{Na}$ sequência, o autor traz o subtítulo Systema actual - algarismo arabicos, informando:

Por mais engenhosos que fossem os artifícios empregados pelos diversos povos para a representação dos números, não havia entretanto uma escripta universal, differia de um povo a outro, desde os caracteres empregados até a maneira de os combinar.

O systema que depois chegou a predominar, generalisando-se seu emprego até nossos dias, é, por alguns, attribuido aos árabes, donde o nome de algarismos arabicos dado aos symbolos por elles empregados. Não obstante, essa origem tem sido contestada por alguns autores.

Os symbolos empregados foram a princípio, 1, 2, 3, 4, 5, 6, 7, 8, 9 representativos dos valores - um, dois, tres, quatro, cinco, seis, sete, oito, nove.

Para exprimirem-se os números por meio destes nove signaes era empregado o ábaco que consistia em um quadro dividido em columnas verticaes correspondendo cada uma dellas a uma ordem de unidades, indicada no alto como se vê em seguida. (CASTELLO BRANCO, 1904, p. 19-20).

Há uma breve explicação do uso do ábaco, a partir de exemplos representados em um quadro (figura 2), e a explanação:

Mais tarde, porem, empregou-se um ponto ou o sinal II para preencher as columnas onde não houvesse unidades; e assim, é que no quadro (...) vemos representados os números cinco mil oitocentos e quatro, e quatro mil e trinta. Appareceu desde então um décimo signal na escripta dos números o qual tomou depois as formas $\odot$ e $\bigcirc$, recebendo o nome de zero; e foi, com o uso, naturalmente modificado, até adquirir a forma que hoje tem 0 .

Com a introducção do zero no systema de signaes, tornaram-se inúteis e foram portanto supprimidas as indicações do ábaco.

(...) Deste então não houve mais necessidade das columnas do abaco e este foi posto de parte; e o zero que, por si só, nenhum valor tem, tornou-se um algarismo imprescindível para assignalar as ordens onde não haja unidades. (CASTELLO BRANCO, 1904, p. 21-22).

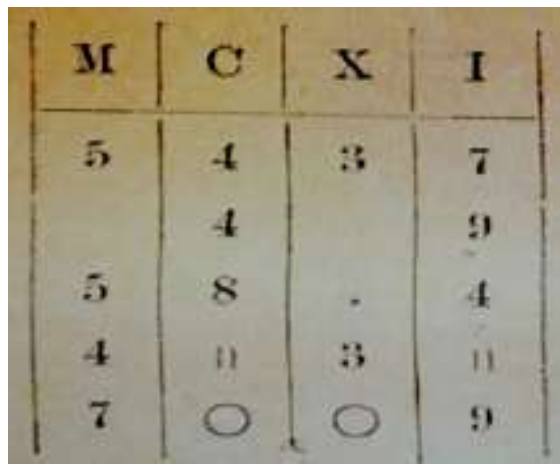

Figura 2 - Exemplos de representação no ábaco

Fonte: Castello Branco (1904, p. 20). 
Elenice de Souza Lodron Zuin

Aspectos históricos dos sistemas de numeração em um livro de aritmética publicado no Ceará em 1904

Esses dados agregam informações históricas relevantes sobre o surgimento e a evolução da representação do zero como um algarismo, ainda que seja de modo sucinto. ${ }^{4}$

Relativamente ao sistema posicional, o autor salienta, em nota de rodapé:

A creação deste principio e sua imposição como base sobre a qual devia assentar o systema de numeração escripta, seria, sem duvida, uma gloria para o inventor de tal systema. Prefiro, entretanto, admittir que elle tenha surgido naturalmente da observação dos factos, a que deu logar a introducção do zero no systema. (CASTELLO BRANCO, 1904, p. 22).

Castello Branco ressalta alguns aspectos, fazendo citações diretas de Hoeffer (sic) e Comberousse:

\begin{abstract}
O valor de posição ou relativo dos algarismos data do século IX de nossa era, sendo Mohammed Iben Mousa (Alkarismi) "o primeiro que teve a idea tão simples e tão luminosa - uma verdadeira revolução scientifica" - de dar a cada um dos signaes numeraes, desde zero até nove inclusive, valores de posição, fazendo-os occupar da direita para esquerda, a primeira ordem pelas unidades, a segunda pelas dezenas etc.

"Alkarismi fazia incontestavelmente uso do zero e designava pelo nome de differença o que se chama hoje posição ou ordem decimal; porque diz que os nove signaes podem achar-se em differentes logares; e que, se uma differença fica vaga põe-se um pequeno circulo para indicar que nenhum numero ahi se acha. Entretanto foi muito lenta a propagação do systema, e só no seculo XVI tornou-se commum seu emprego.

De Comberousse diz: "A notação romana foi empregada no occidente até a introdução dos algarismos arábicos. Fixa-se esta introducção no fim do século X."

E ainda do mesmo autor: "Só em 1500 tornou-se commum seu uso em França. Continuou-se durante muito tempo a empregar simultaneamente os dois systemas. Escrevia-se por exemplo $\mathrm{X}^{1}, \mathrm{X}^{2}, \mathrm{X}^{3}$, por $11,12,13$. A própria forma dos algarismos soffreu variações e só em 1650 ficou assentada definitivamente." (CASTELLO BRANCO, 1904, p. 25-26).
\end{abstract}

Com esse caráter, que pode ser considerado um diferencial e, de certo modo, algo inovador para a época, Castello Branco se referencia em autores que ele considerava trazer informações fidedignas. Inicialmente, suspeitamos que o autor citado Hoeffer, na verdade, tratava-se do germano-francês Johan Christian Ferdinand Hoefer (1811-1878), que escreveu sobre a história das ciências e publicou a obra Histoire des Mathématiques. No livro de Castello Branco, está grafado V. Hoeffer - e, provavelmente, trata-se de um erro tipográfico. Fizemos a conferência, consultando minuciosamente a referida obra, e confirmamos que as citações de Castello Branco

\footnotetext{
${ }^{4}$ Algumas das informações do livro de Castello Branco também são encontradas no Curso elementar de matemática: Arithmetica, de autoria de Aarão e Lucano Reios.
} 
Elenice de Souza Lodron Zuin

Aspectos históricos dos sistemas de numeração em um livro de aritmética publicado no Ceará em 1904

foram realmente retiradas da mesma. Como foi apontado anteriormente, outro autor mencionado por Castello Branco é Charles de Comberousse ${ }^{5}$ e, em sua obra, existem poucas abordagens factuais referentes aos sistemas de numeração.

Em um primeiro momento, poderíamos julgar que as informações históricas no século XIX não traziam a origem dos algarismos utilizados, hoje, no Ocidente, como uma ideia original dos povos do Vale do Rio Indo, que foi divulgada, em parte, pelos árabes e, por esse motivo, originou-se a denominação "algarismos hindu-arábicos". 6 Porém, ao consultar a obra de Hoefer, constatamos que existe a indicação de que o sistema indiano é formado sucessivamente, tendo nove símbolos e o zero, e que seu valor de posição não foi "importado" do Irã (país dos Aryas ocidentais) para o solo hindu pelos Aryas orientais, falantes do sânscrito, pois não se encontram traços entre os Aryas ocidentais, que falavam o zend ${ }^{7}$.

Hoefer faz todo um discurso a respeito do sistema posicional e da sua possível elaboração entre os hindus. Ressalta, inclusive, que F. Woepke, "um erudito matemático e orientalista, tentou fazer prevalecer a opinião de que os símbolos indianos foram transportadas de Bagdá para o Egito sob diferentes formas, aquela que os árabes do Oriente o adotaram, e o que conhecemos sob o nome de figuras de Gobar." (HOEFER, 1874, p. 54 - tradução nossa).

As figuras de Gobar ou Ghubar (areia de mesa ou pó de mesa ${ }^{8}$ ) se constituem em variantes dos algarismos hindus originais, os quais passaram por transformações; são caracteres específicos que deram origem à grafia moderna dos algarismos utilizados no Ocidente (figura 3). As figuras de Gobar teriam sua gênese na Arábia ocidental, sendo introduzidas na Espanha por volta do ano 1000 pelos árabes, os quais, nesse sentido, colaboraram para sua difusão na Europa ocidental. (WALL, 2014).

\footnotetext{
${ }^{5}$ Charles Jules Félix de Comberousse (1826-1897) foi um professor de Francês e Matemática em terras francesas.

${ }^{6} \mathrm{Na}$ Índia setentrional, já se utilizavam símbolos numéricos desde o século III a.C. (IFRAH, 2010).

${ }^{7} \mathrm{O}$ zend era um antigo idioma da Pérsia. Zend também se denominavam os livros de Zoroastro, escritos nesta língua, de acordo com a opinião de autores orientais e segundo a prova experimental que se tem destes livros, que ainda existem em língua zend e com letras zéndicas (caracteres especiais para este idioma). Ao que parece, esta língua e letra eram utilizadas no país de nascimento de Zoroastro. Este idioma ainda é encontrado em alguns países. Do zend, teriam se derivado os idiomas pa-zend, peblvi e parsi. (HERVÁS Y PANDURO, 1801).

${ }^{8}$ Essa referência à areia ou pó é devido ao fato de se fazer uso do "ábaco de areia", comum na tradição oriental, constituindo-se em "um tabuleiro de madeira coberto de areia ou cera, onde se delimitavam as colunas sucessivamente e onde se escreviam as cifras com os dedos ou com um estilete" (FERREIRA, 2008, p. 46). Hoefer (1874) indica que as figuras de Gobar foram descobertas por Antoine-Isaac Silvestre (barão Silvestre de Sacy), em um antigo manuscrito da biblioteca de Saint-Germain de Prés. Afirma que os sinais são pontos para indicar o zero. Desta forma, 30 era representado por $3^{\circ}, 400$ por $4^{\circ \circ}$ etc.
} 


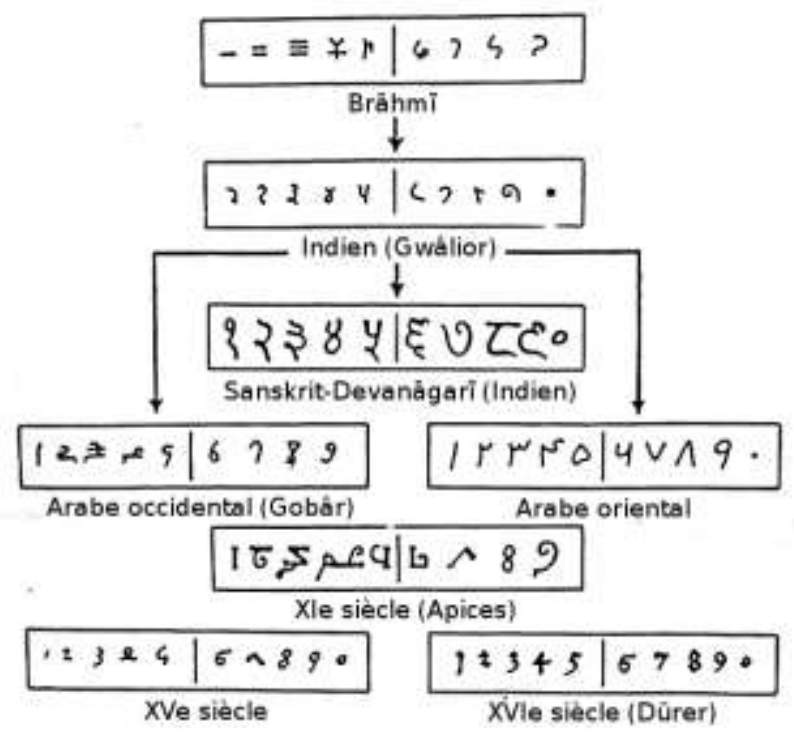

Figura 3 - Genealogia dos algarismos do sistema decimal de numeração Fonte: http://www.wikiwand.com/mwl/Algarismos_ando-arábicos

O “ábaco de pó” tinha uso no Oriente, porém, há indícios de sua utilização no Ocidente greco-romano, juntamente com o ábaco de fichas. O "ábaco de pó" consistia em uma "tabuleta munida de um quadro com as bordas levantadas, que se preenche de areia fina, sobre a qual delimitam-se colunas sucessivas e no qual se traçam algarismos com o dedo ou uma ponta." (IFRAH, 1997, p. 438).

Hoefer (1874) não defende que a origem do sistema de numeração seja devida ao povo do vale do Rio Indo. Ainda salienta: quem criou a designação "números indianos" foram os próprios árabes e que isso teria culminado na ideia de que os algarismos teriam origem entre os indianos. Em seguida, acrescenta: Glarean, em 1554, e o P. Goar, em 1654, queriam rejeitar o nome dos algarismos arábicos aplicados aos símbolos modernos dos algarismos então utilizados. Todavia, o que Castello Branco registra em seu livro é o termo "algarismos arábicos".

Não é mencionado o nome de Gerbert de Aurillac (950-1003), que foi o papa Silvestre II $^{9}$, e quem teria apresentado ao Ocidente cristão os algarismos indo-arábicos.

\footnotetext{
${ }^{9}$ Gerbert de Aurillac foi o primeiro papa de nacionalidade francesa. De acordo com Ferreira (2008, p. 45), atualmente, "se tem como certo que foi Gerbert que introduziu na Europa cristã o sistema de numeração arábico, quando escreveu seu tratado - muito confuso para a época - do uso do ábaco.” Talvez, por isso, Hoefer (1874) não mencione Gerbert de Aurillac em sua obra.

Gerbert d'Aurillac elaborou "um ábaco, no qual esse tipo de numeração aparece, mas sem o zero, que era desconhecido mesmo pelos árabes da Península Ibérica. Com a escrita dos algoritmos das operações, apareceu, então, a necessidade do zero, para designar a(s) coluna(s) vazia(s) que havia no ábaco. Esta
} 
Elenice de Souza Lodron Zuin

Aspectos históricos dos sistemas de numeração em um livro de aritmética publicado no Ceará em 1904

Igualmente, não se registra o papel de Leonardo Fibonacci (ca 1170-1240), com sua obra Liber abaci ( $O$ livro dos ábacos), a qual trazia explicações sobre o sistema posicional relativo ao sistema de numeração criado no Vale do Rio Indo (local onde é atualmente o Paquistão) e as regras de operações aritméticas. Sendo o Liber abaci reconhecidamente "o livro mais importante no desenvolvimento da matemática européia. Foi acessível primeiramente aos comerciantes e banqueiros, que estabeleceram assim as bases para a economia moderna na Europa". (D'AMBROSIO, 1996, p. 44). No texto de Castello Branco, só é evidenciado o nome de Al Kowarismi (ca 780-850).

Embora Hoefer (1874) discorra sobre os sistemas de numeração dos babilônios, egípcios e de outras civilizações, Castello Branco não os acrescenta em sua Aritmética. Em relação aos algarismos romanos, Hoefer sustenta que IIII poderia representar IV e, o símbolo $\supset$ corresponder a $\mathrm{D}$, o que está correto. Outros equívocos, concernentes às informações históricas, se situam em colocar os algarismos romanos modernos como se fossem os primeiros elaborados por aquele povo. Na sua origem, os algarismos romanos eram bem distintos e passaram por transformações até chegar à forma que conhecemos (IFRAH, 1997). No entanto, esse tipo de dado errôneo é algo também divulgado em diversos livros didáticos de Matemática atualmente.

Outras informações que Castello Branco inclui no tópico numeração:

É devida a Viette, século XVI, a substituição de mil mil, como era então designada a $3^{\mathrm{a}}$ classe, pela palavra milhão.

A palavra bilhão parece ter sido empregada pela primeira vez em 1665 pelo jesuíta Taquet, que dividia os números em classes sextenaria. Semelhante sistema foi porem logo abandonada, sendo adoptada desde então a divisão dos números compostos em classes ternárias de unidades, milhares, milhões, bilhões, trilhões etc. (CASTELLO BRANCO, 1904, p. 13-14).

Constata-se que Castello Branco fundamenta-se em mais de um autor para conduzir os apontamentos históricos em seu livro, sendo esta citação anterior retirada da Arithmetica de Aarão e Lucano Reis, como ele mesmo indica.

\section{À guisa de considerações finais}

Castello Branco mostra-se um autor que, em alguma medida, parece fazer um esforço para inovar e desfazer os laços com tradicionalismo na introdução do ensino de

introdução foi feita na Europa por Fibonacci, em 1202, no seu famoso tratado Liber Abaci." (FERREIRA, 2008, p. 54). 
Elenice de Souza Lodron Zuin

Aspectos históricos dos sistemas de numeração em um livro de aritmética publicado no Ceará em 1904

Aritmética no início do século XX. Os aspectos históricos dos sistemas de numeração, presentes no livro, definem outro tom para o trabalho com os alunos. Seria uma tentativa de provocar mudanças na cultura escolar daquela época? Como fundador, diretor e professor do Instituto Manuel Borges, no espaço nuclear da sua instituição, Castello Branco poderia integrar novos saberes e novas práticas. Ele escreveu todos os compêndios utilizados no Instituto do primeiro ao quarto anos do ensino primário.

O filósofo Djacir Lima Menezes, ex-aluno dessa escola, assim descreve o antigo diretor:

\begin{abstract}
Creio que jamais houve diretor mais presente e participante da vida de uma comunidade escolar. De uma autoridade impressionante, assegurava, sem quaisquer recursos a castigos físicos, exceção de alguns cocorotes nos mais irrequietos, a tranqüilidade e obediência do alunado. Recordando a sua figura, escreve a filha: "lembro-me, entretanto, de sua grande austeridade em todas as cousas, que era dotado de grande coragem, extraordinariamente enérgico; de uma justiça ímpar e, ao lado de tudo isso, um coração extremamente sensível". São, realmente, estes traços que ficaram indeléveis na memória das gerações que tiveram a dita de o terem como mestre. (MENEZES, 1989, p. 171).
\end{abstract}

Menezes (1989) ainda pontua que o Instituto abrigava uma estrutura curricular que o distinguia das demais instituições escolares. Cita os professores Arquias Medrado e Henrique Autran, os quais tinham formação positivista, porém, segundo seu ponto de vista, Castello Branco não se enquadrava na figura de um seguidor do positivismo ${ }^{10}$.

É necessário assinalar que, em fins do Oitocentos, o Brasil assiste a uma difusão de ideias estrangeiras, entre elas o positivismo de Auguste Comte. Ocorre grande divulgação de autores franceses no país, "os cientistas brasileiros acompanharam as ideias dos pensadores europeus e relacionaram estes aos problemas político, econômico, e sociais no Brasil”. (DANTES; HAMBURGUER, 1996, p. 50).

Miguel e Miorim (2004) sustentam que a "influência do positivismo no Brasil, particularmente entre finais do século XIX e começos do XX, seria uma fator decisivo e reforçador de várias formas de participação da história em livros didáticos e propostas oficiais brasileiras.” (p. 38). A marca do positivismo fez-se sentir com Benjamin Constant na reforma do ensino secundário, através do Decreto n. 981, de 8 de novembro

10 A história das ciências é exaltada por Comte na segunda lição do seu Curso de Filosofia Positivista: "Estamos por certo convencidos de que o conhecimento da história das ciências é da mais alta importância. Penso, ainda, que não conhecemos completamente uma ciência se não conhecemos sua história. Mas este estudo deve ser concebido inteiramente separado do estudo próprio e dogmático da ciência, sem o qual essa história não seria inteligível”. (COMTE, 1996, p. 55). 
Aspectos históricos dos sistemas de numeração em um livro de aritmética publicado no Ceará em 1904

de 1890. O objetivo central era romper com a formação clássico-humanista que prevalecia no ensino secundário e promover uma mudança, fornecendo uma formação científica aos estudantes. A instauração dos princípios positivistas nos estabelecimentos escolares se daria com outro modelo de programa curricular.

A análise dos livros que Castello Branco diz se referenciar indica que não há quaisquer abordagens históricas nos Elementos de Arithmetica, de João José Luis Vianna; tão pouco, no Tratado Elementar de Arithmetica, de Serrasqueiro. Então, esses autores não teriam nenhuma influência no sentido de Castello Branco integrar algumas informações históricas em seu texto.

De um modo geral, o livro de Aritmética, de Comberousse, que Castello Branco cita, é Cours de Mathématiques, tendo alguns poucos pontos de semelhança com o seu texto. A Arithmetica dos irmãos Reis aborda diversos aspectos históricas sobre o sistema de numeração indo-arábico. Dentre eles, alguns coincidem com o que Castello Branco integra em seu livro, entretanto, muitas informações presentes na obra dos irmãos Reis não figuram nas Lições de Arithmetica.

Não tivemos acesso a outros livros mencionados, como Arithmetica dos autores Samuel de Oliveira e Liberato Bittencourt; este último era positivista. O quinto volume de sua obra Curso Completo de Matemática elementar, sem notas históricas, traz uma sessão preliminar na qual o autor informa se pautar nas prescrições de Comte, assim como segue as orientações positivistas o autor Luis Celestino de Castro, no qual Castello Branco também diz se fundamentar.

O que faz Castello Branco tomar a decisão de incluir referências históricas em seu livro? Ele passou por uma formação positivista e tinha conhecimento da obra de Comte, pois faz referência ao mesmo em seu livro e utiliza autores que seguem essa corrente filosófica. Ele também cita Aarão Reis, outro positivista. Entendemos que a valorização da história no livro de Castello Branco poderia estar ligada às suas concepções comteanas, as quais colocam em relevo a História das Ciências. Esta seria uma hipótese plausível. Verificamos que Castello Branco claramente incorpora em seu livro dados encontrados da obra Histoire des Mathématiques, de Hoefer - este é o elo mais forte.

Outro fato a ser destacado é que os irmãos Lucano Reis e Aarão Reis publicaram manuais de aritmética (1892) e álgebra (1902) contendo diversas notas históricas da matemática e uma perspectiva de progresso histórico, com clara influência positivista, 
Elenice de Souza Lodron Zuin

Aspectos históricos dos sistemas de numeração em um livro de aritmética publicado no Ceará em 1904

como é apontado por Gomes (2008). Castello Branco tinha conhecimentos das obras dos irmãos Reis, inclusive fazendo menção e citações referentes ao livro Curso elementar de matemática: Arithmetica, podendo ter sido influenciado pelas informações históricas que esses autores incorporaram em seus textos e não, necessariamente, por ele estar ancorado na doutrina positivista (?).

As abordagens históricas contidas no livro de Castello Branco se restringem aos tópicos sobre sistemas de numeração e, posteriormente, só há uma pequena nota histórica no capítulo relativo a logaritmos. Ainda assim, Castello Branco integra a História da Matemática de forma efetiva, levando-o a fazer parte de um pequeno grupo de autores que privilegiava a condução saberes matemáticos ancorados na história.

Trazemos, novamente, as palavras de André Chervel (1990) sublinhando que os conteúdos passam por transformações e a função das disciplinas escolares "consiste, em cada caso, em colocar um conteúdo de instrução a serviço de uma finalidade educativa." (p. 188). A Castello Branco sobrepunha-se uma finalidade educativa acima de quaisquer rendimentos financeiros que suas obras pudessem fornecer? Sua opção por conduzir um dos tópicos do seu livro, com uma abordagem distinta, parece revelar suas concepções sobre o ensino dos sistemas de numeração, que ele primaria por dar outro tratamento.

Ao incluir componentes históricos para os saberes aritméticos, seria possível mudar sua recepção, ao trazer um caráter social, das necessidades humanas de matematizar o mundo, reorientar-se-ia o olhar e o interesse dos estudantes pela matéria. Talvez, essa possa ter sido a real aspiração de Odorico Castello Branco.

\section{Referências}

BITTENCOURT, Liberato. Curso completo de Matemática elementar. Geometria. Santos: Oficinas Gráficas do Ginásio, 1922. v. 5.

CASTELLO BRANCO, Odorico. Lições de Arithmetica. Fortaleza: Typographia Minerva, 1904.

CHERVEL, André. História das disciplinas escolares: reflexões sobre um campo de pesquisa. Teoria \& Educação, n. 2, p. 177-229, 1990.

COMBEROUSSE, Charles de. Cours de Mathématiques. A L'usage dês candidats a L'École Polytechnique, a L'École Normale supérieure, a L'École Centrale des Arts et Manufactures. 3. ed. Paris: Gauthier-Villars, 1884. (Tome I).

COMTE, vida e obra. São Paulo: Nova Cultural, 1996. (Os pensadores) 
Aspectos históricos dos sistemas de numeração em um livro de aritmética publicado no Ceará em 1904

D’AMBROSIO, Ubiratan. Educação matemática: da teoria à pratica. Campinas: Papirus, 1996.

DANTES, Maria A.; HAMBURGER, Amelia I. A ciência, os intercâmbios e a história da ciência: reflexões sobre a atividade científica no Brasil. In: HAMBURGER, Amélia I. et al. A ciência nas relações Brasil-França (1850-1950). São Paulo: Edusp, 1996.

FERREIRA, Eduardo Sebastiani. O ábaco de Silvester II. Revista Brasileira de História da Matemática, v. 8, n. 15, p. 43-55, abr. 2008.

GOMES, Maria Laura M. História da Matemática e positivismo nos livros didáticos de Aarão Reis. Revista Brasileira de História da Educação, n. 18, p. 69-94, set./dez. 2008.

HERVÁS y PANDURO, Lorenzo. Catálogo de las lengua de las naciones conocidas, y numeracion, division, y clases de estas segun la diversidad de sus idiomas y dialectos. Lenguas y naciones de las islas de los mares Pacífico e indiano austral y oriental, y del continente del Asia. Madrid: Imprenta de la Administración del Real Arbitrio de Beneficencia, 1801. v. II.

HOEFER, Ferdinand. Histoire des Mathématiques - depuis leurs origines jusqu'au commencement du dix-neuvième siècle. Paris: Typographie Lahure/ Librairie Hachette et Cie, 1874.

IFRAH, Georges. História universal dos algarismos: a inteligência dos homens contada pelos números e pelo cálculo. Rio de Janeiro: Nova Fronteira, 1997. v.1.

IFRAH, Georges. Os números: a história de uma grande invenção. 11. ed. São Paulo: Globo, 2010.

MENEZES, Djacir. Evocação de um pioneiro: Odorico Castelo Branco. Revista de Ciência Política, Rio de Janeiro, 32(4), p. 170-171, ago./out. 1989.

MIGUEL, Antonio; MIORIM, Maria Angela. História na Educação Matemática propostas e desafios. Belo Horizonte: Autêntica, 2004.

REIS, Aarão; REIS, Lucano. Curso elementar de matemática: Arithmetica. 2. ed. Rio de Janeiro: Francisco Alves, 1892.

SERRASQUEIRO, José Adelino. Tratado elementar de Arithmetica. 22. ed. Coimbra: Livraria Central de J. Diogo Pires - Sucessoras, 1926.

WALL, Edward S. Teoria dos números para professores do Ensino Fundamental. Tradução de Roberto Cataldo Costa. Porto Alegre: AMGH Editora Ltda/McGraww Hill Education, 2014.

VIANNA, João José Luis. Elementos de Arithmetica. 11. ed. Rio de Janeiro: Francisco Alves, 1906. 
Elenice de Souza Lodron Zuin

Aspectos históricos dos sistemas de numeração em um livro de aritmética publicado no Ceará em 1904

ZUIN, Elenice de Souza Lodron; SANTOS, Célio Moacir. Abordagens históricas da matemática em "Lições de Álgebra Elementar" de Joaquim Ignácio de Almeida Lisboa. REMATEC, ano12, n. 24, p. 18-38, jan./abr. 2017.

ZUIN, Elenice de Souza Lodron. Livros didáticos como fontes para a escrita da história da matemática escolar. Guarapuava: SBHMat, 2007. (Coleção História da Matemática para Professores). 